\title{
Implicated reading: a method for reflecting on practice
}

\section{Michaela J. Harrison}

Faculty of Education, Manchester Metropolitan University

Brooks Building, 53 Bonsall Street, Manchester, M15 6GX.

Tel.: +441612472069

E-mail address: m.j.harrison@mmu.ac.uk

Michaela J. Harrison is senior lecturer in the Faculty of Education, Manchester Metropolitan University (England). Her research activity includes work aiming to explore the relationship between students' writing and their development as professionals. Her research and theoretical interests include; post-structuralism, feminism, new-materialism, practitioner research and writing as a form of enquiry. She received her EdD from Manchester Metropolitan University. 


\begin{abstract}
This paper evaluates an attempt by the author to operationalise the theory of reflective practice within the context of initial teacher education. Whilst an integral element of many teacher education programmes, the problematic of 'how' to reflect on practice remains a concern. In response, and taking inspiration from the work of Deleuze and Guattari, specifically their critique of representational thought and common understandings of text, the author experiments with a method for reflecting called implicated reading. The method involves the reading of students' lived experiences as beginning teachers (recorded in written form), against a variety of other texts. The author draws on interview data to analyse and discuss the merits of the approach. The paper concludes that the method of implicated reading has the potential to unsettle the common tendency to focus on meaning and interpretation when reflecting on events and experiences. It is argued that the student teachers involved in the project instead begin to experience reflection as a process of connectivity, rethinking pedagogy as a result.
\end{abstract}

Key words: implicated reading; student teachers; teacher education; reflection; Deleuze and Guattari

\title{
Introduction
}

The intention of this paper is to contribute to the body of work that considers how the process of reflection might be reified in teacher education programmes. Reflective practice has become somewhat synonymous with university-based teacher education programmes; Beauchamp and Thomas (2010) describing it as a 'central activity in teacher development'. As a pedagogical device, Clandinin and Connelly (2000) attribute the popularity of reflective practice to the ways in which it enables those involved in teacher education to tell an alternative and more personalised story about what it might mean to be and become a teacher; a story that runs counter to the prescribed and technical version often presented by policy makers. However, its popularity is not indicative of consensus or consistency in either the definition of reflection or in how the process of reflection is operationalised and implemented (Nelson \& Sadler, 2013). Rather than view this lack of consensus as a problem, the author takes the view that plurality allows teacher educators the space and opportunity to experiment 
with approaches that might have otherwise gone unthought should a consensus on a reflective method exist. This paper details and evaluates the impact of one such pedagogical experiment, conducted in a university in England with a large teacher education programme and consisting of a set of activities designed to provide student teachers with an alternative method for reflecting on practice. It is heavily influenced by Deleuzo-Guattarian ontology and the writings of contemporary Deleuzian scholars thinking with and putting to work their theory in qualitative research (Mazzei \& McCoy, 2010). It is the author's contention that in synthesising Deleuzo-Guattarian perspectives with the practices of reflection, that teacher educators may discover new ways in which reflective practice might be operationalised. The method described and evaluated in this paper, offered the author a means of refining and extending the kinds of reflective activities student teachers were already undertaking as part of their teacher education programme; that is, writing accounts of their experiences in school in the form of a learning journal and later subjecting these to critical reflection. These accounts most usually take the form of descriptions of events or sets of circumstances that have troubled or ignited curiosity in the student. In addition to these recollections, students often include their understanding or interpretations of the situations and events as they occurred or which they have gleaned subsequently in the intervening period between the experience and committing it to paper (or digital equivalents). Keeping a learning journal has many advocates and potential benefits (Farrell, 2013; Holly, 1989; McGarr \& Moody, 2010; O’Connell \& Dyment, 2011) and many student teachers have become familiar with the expectation to produce them. However, it is what students do with these accounts of practice once written, or what they might offer in terms of developing student teachers' thinking and practice, that is the area of particular interest for the author and the focus of this paper. In and of itself, journal writing does not produce critically reflective learning; especially when, as Cowan (2014) notes, they simply require or encourage narrative 
reporting. Considering this, and responding to calls such as those from Nelson and Sadler (2013) for the operationalisation of reflective practice with a robust theoretical basis, the author recognises the potential in Deleuzo-Guattarian philosophy for developing curriculum activities that both constitute theoretically grounded reflective practice, but also challenge potentially restricting, common place notions of writing, thinking and reflection.

The design and implementation of the reflective method detailed in this paper, draws heavily on the work of Donna Alvermann (2000), in particular her experimentation with a method for interrogating data which she refers to as implicated reading (a phrase originally coined by Pearce, 1997) and which was also inspired by Deleuze and Guattari. Alvermann's work involved the rethinking of data gathered as part of a research project; a project which, for all intents and purposes had been completed, the data analysis having been conducted, conclusions drawn and papers published. Alvermann's version of the implicated reading process involves several stages. It begins with re-readings of empirical material (existing as a result of the 'normal' research activity Alvermann had undertaken for her original project) whose merit and meaning had already been determined. These 're-readings' (of interview transcripts and field notes) are informed by a selection of additional texts less commonly associated with the research process. These additional texts, although varied in form and genre, are all loosely labelled 'popular culture'; for example the television serial cartoon South Park is selected.

Alvermann (2000) reads the popular culture texts 'against' the empirical material. This process constitutes 'implicated reading'. It enables Alvermann to decentre and disrupt the smooth readings of text that occur when one works under the assumption that texts signify meaning. Seeking out connections between the seemingly disparate texts in interesting and creative ways means 'remaining open to the proliferation of ruptures and discontinuities that in turn create [new] linkages' (2000, p. 118). Dimitradis and Kamberelis 
explain the process as allowing the creation of 'possible realities by producing new articulations of disparate phenomena' (as cited in Alvermann, 2000, p.116). In so doing, Alvermann poses a series of questions to the texts focussing specifically on how they connect with both herself as the reader/researcher and with the other texts. The intention is to consider text in the Deleuzo-Guattarian sense, as an agent that acts outside of itself rather than as a portal to meaning.

The potential of implicated reading as a means of operationalising reflection was deemed significant enough for further enquiry by the author for several reasons. The first and most pronounced of these is exemplified in the following excerpt from Alvermann's (2000) writing;

'...texts... are typically thought to signify meaning, albeit meaning that is contingent upon the interaction of subject (reader) and context. Less typical is Deleuze and Guattari's (1986/1980) concept of text, which is predicated on their particular decentring project - the avoidance of any orientation toward a culmination or ending point. Analysing texts from Deleuze and Guattari's perspective, it is how the texts function outside themselves that is of interest. This interest stems from the belief that texts, likes rhizomes, connect with other things (e.g., readers, other texts and contexts).'

(p. 117)

This simple description of a refusal to associate textual analysis with meaning allowed for an alternative conception of how students' journal writing might be utilised. As a teacher educator, the author has often noticed students' tendency to assume that the written accounts they share in taught sessions have in some way managed to capture or reveal truth (MacLure, 2003), allowing their readers (other students or their tutor) access to 'things that actually happened'(ibid.). Indeed, this belief in 'textual transparency', as noted by Gilbert (1989), is a common tendency, especially within educational settings where 'writing is frequently regarded as a transparent medium through which the 'person behind the text' can be seen' ( $p$. 22). However, as Brodkey (1987) warns, a narrative of experience and experience itself 
should never be confused as one and the same thing. Alvermann (2000) suggests that an alternative is possible. Instead of asking what the text might mean (i.e. what is going on in the text/journal entry? What am I doing and why?), she asks, how does it function and in what ways does it connect to the reader, other texts and contexts? (I.e. what does the journal entry do to the other texts I am reading and vice versa? How, and in what ways, do I connect with the writing?) In other words, the focus shifts, from what is happening within the text, to how the text functions outside of itself. In the first instance, this alternate conception of text was deemed worth exploring, its potential to disrupt and challenge common practices promising a reinvention of the reflective space.

\section{Implicated reading: what it entailed}

A series of teaching activities were designed based on the implicated reading principles and processes. Firstly, and rather straightforwardly, it was decided that the journal writing that students produced would constitute one 'text' and that these would perform a similar function to that of Alvermann's (2000) empirical data. It was hoped that the reading of these texts and the process of making use of them, would be reinvigorated by the introduction of an additional set of texts, similar to those that Alvermann worked with, which would be read alongside the journal entries with similar questions to Alvermann's posed to the transreading process.

Taught elements of the students' initial teacher education programme already allowed significant space for the students' analyses of, and critical discussion around, their learning journal entries. The author took advantage of the opportunity these spaces offered, supplementing them with the implicated reading activities. The student teachers were already aware of the working practices of their course and the requirement that they would be expected to scrutinise and critically reflect on their journal writing in small groups. For the 
purpose of this study, each student was asked to choose at least one journal entry to present for discussion to a small group of peers. Each discussion was preceded by an introduction to an additional text and a tutor-led taught input on the purpose and method of implicated reading. Usually, some time was spent exploring the additional text, familiarising ourselves with its content (watching or reading) and in most cases an impromptu 'comprehension' activity would follow. As with Alvermann (2000), the additional texts that were selected could all be loosely labelled as popular culture.

The rationale behind the choice of additional texts varied. Some were chosen for their association to the educational settings for which the students were training. Harry Potter and the Philosophers Stone (Rowling, 1997) and The Rainbow Fish (Pfister, 1996) are both children's stories, the former usually read with/to older children, the latter a picture book commonly used in the Early Years. Both reflected the working environs of the students and, as such, it was hoped they would offer some value added profitability (at the very least, the students would leave with an additional layer of understanding of some popular children's literature). Other texts were chosen because their content was thought rich enough to fuel powerful implicated readings. The film/motion picture Amélie (Ossard and Jeunet, 2001) was chosen for this reason. It was hoped this narrative depth, or 'all the funny little curlicues and jottings around the action' (Mitchell, 2001) would encourage multiple readings, the students taking what they wished from a wider array of possibilities. As in Alvermann's (2000) study, the implicated readings were structured using a series of questions:

1) How do the texts function?

2) What does the journal entry do to the other texts I am reading and vice versa?

3) How, and in what ways, do I connect with the texts?

The students were also offered modelled examples of the process in order that they could 'see' how implicated reading might work in practice. 
The project was conducted with a cohort of 28 students, all in the final stages of their initial teacher education. All 28 students experienced the implicated reading activities. They were assured that the activities were simply an alternative method for reflecting and, as such, in-keeping with the course philosophy and content with which they were familiar. The course's learning outcomes would still be met, just with a change to the method or process by which they might be achieved. It was also made clear that the altered activities they experienced would be evaluated as part of a wider research project and should they be involved in anything that involved the collection of data, their consent would be sought.

Towards the end of the academic year, and after the taught course had finished, students were asked to volunteer themselves, in their small groups, as potential interviewees. Every student in each small group needed to be willing to volunteer for the group's offer to be interviewed to be accepted. Of the 28 students in the cohort, two small groups volunteered themselves for interview; eight students in total, four students in each group. Of these eight students, seven students attended and completed one-to-one interviews with the author (the project's principal researcher), at a time of their choosing, of between 30 minutes and one hour in duration. The eighth volunteer, failed to attend at the agreed time and did not respond to a follow-up email invitation to rearrange. The interviews were semi-structured and were intended to encourage the students to reflect and comment upon the implicated reading activities. The seven interviewees were asked two questions in relation to the process of implicated reading. One was intended to provoke general commentary (did any of these [additional popular culture texts] help you to consider your own teaching or writing differently?) and another in the hope that it would furnish more specific examples (what connections, if any, did you make between the texts we worked with?).

The interviews were audio recorded and transcribed in full by the author/researcher. The seven interviewees were asked to consent to the use of their interview transcripts as data. 
Consent forms included an explanation that their interview responses may be included in publications and papers disseminated to a wider audience. Institutional ethical approval for the project was sought and granted.

It is important to note that as both the project's principal researcher and the students' academic tutor, the author occupied a somewhat problematic position within the research. Tensions and dilemmas associated with this position are well documented in research texts which identify the key issue as one of power. Somekh et al. (2005), for example, explain that whilst power differentials are a feature of most, if not all types of research, the extent and ways in which they are played out depends upon the nature of the relationship between the researched (the research participants) and the researcher. In the case of this project, it might be argued, that as the participants' academic tutor, the author/researcher occupied a position of authoritative power. In such a situation, questions about whether the participants felt pressured (either consciously or subconsciously) to respond in certain ways during activities designated as part of the research project loom large.

However, as Somekh et al. (2005) also note, whatever the stance or position the researcher adopts in relation to her participants and whatever constitutes the relationship between them, power differentials can never be excised and can never be totally within the researcher's control. This means that whilst attempts were made to mitigate the potential effects of the researcher/researched relationship, for example, by adopting a conversational tone and language style during the interviews to put the participants at ease (Magnusson \& Marecek, 2015), there is no way of knowing to what extent this was successful or in what ways the relationship effected the participants' answers. As Somekh et al. conclude, this ambiguity and uncertainty is a facet of qualitative research to which researchers have to surrender any hopes of control. 
However, this is not to say attempts to mitigate against any undesirable effects of the relationship cannot be made. For example, in order to allay any concerns that additional favour might be bestowed upon the interviewees by the researcher (as their academic tutor) for example, in gratitude for their time, effort, or indeed supposed 'correct' responses, the interviews were conducted after the taught course had ended and therefore, so too, the mainstay of the student-tutor relationship. In addition, allowing interviewees to select the interview time and date also helped lessen any disadvantage the participants might have experienced in terms of burdens on their time.

The project was inspired by the notion proffered by Gale (2010) that Deleuzo-Guattarian philosophy might best be thought of as a 'philosophy of use'. This 'useful' quality is exemplified by Gale in his own application of Deleuzian theory to inject 'aesthetic and ethically sensitive' (2007, p. 471) qualities into teacher education. Similarly, this paper details a concerted effort to put the theory of Deleuze (and Deleuze and Guattari) to work with the aim of transforming or enhancing a particular aspect of teacher education; specifically, the practice of reflection. In realising these aims, the project adopted a 'classroom action research' methodology (Kemmis \& McTaggart, 2000). This form of research typically involves classroom teachers using qualitative modes of enquiry to make judgments about and improvements to their own practice. It has, increasingly, however, been applied similarly by university tutors to do the same (Noffke \& Somekh, 2005). The project made use of Lewin's 'stages' of action research (Lewin, 1988, cited in Noffke \& Somekh, 2005). This paper, however, describes only a small portion of the project as a whole. The stages of action research detailed here include; hypothesising regarding potential concerns in the functioning of an object under study (in this project the 'object' being reflection); conjecturing possible resolutions which are subsequently actualised as forms of action (in this project, implicated reading) (ibid.) and finally, testing the hypothesis via evaluation of the actions implemented (analysing participants' interview responses) (Somekh, 2006). 
The interview transcripts were analysed by the author/researcher. The goal of the analysis was to identify significant details and generate insight into their potential meaning. Strategies employed in the analysis included; noting patterns, process coding and finally, catergorising into themes (Saldaňa, 2014). The themes of connectivity and rethinking pedagogy emerged as significant and are the subject of the discussion below.

\title{
Data and discussion of emergent themes
}

\section{Data}

It was hoped that as a result of the implicated reading activities, students would begin to contemplate text (in particular, their journal writing) in less typical ways, experiencing the text and its connectivity with other texts and themselves, rather than viewing the text as a singular, discrete and stable entity from which they could extract meaning. Several students, during interview, commented on the ways in which implicated reading had allowed them to do this. Student A and Student B articulate this process through recourse to 'ideas', specifically how and from where ideas about self or practice might be generated.

\begin{abstract}
Student A: That whole approach where you can use any source and you don't know where ideas are going to come from, so it made me go home and when I watched The Wire ${ }^{1}$ I was like, 'oh, that really made me think about this.' And you know, I was just watching something and because I had that mind-set I was trying to make links with my own personal life and my writing.
\end{abstract}

Student B: ...it's the idea of looking at a subtext, is the sort of words that came into my head, which is what we are expected to do I imagine with say the learning journal. You know it's like you say, well I'm actually like this because of this, and only look at the

\footnotetext{
${ }^{1}$ The Wire is an American drama televised in England. Set in the city of Baltimore, each season introduced and explored a different facet of life in urban America.
} 
surface; well, it sort of forces you to look at perhaps other ideas. It made me think about the subtext to my practice I suppose.

Some of the students provided specific examples of the ways in which they had connected with the texts on a personal level:

Student C: I think in some ways the way that Amélie was kind of... I mean she was trying to reassure herself that she was doing a good job, you kind of... I think you analyse everything you do and you're so worried that you are going to do something wrong, or that you're gonna upset someone even, like I worry about the smallest things... even worrying about not like letting a child go to the toilet, thinking you know, maybe they've got some kind of problem. I kind of dramatise things in my head and I worry about that the smallest things that I say or do is going to disrupt things and that kind of process of... I think she kinds of looks back and she needs that reassurance in a way that everything she's done is right, you know like with her family she kinds of analyses everything. I think that's kind of what we do all the time... I think that's a process teachers go through a lot, looking back at themselves and very critical of what we do all the time I think.

Student D: The Harry Potter one... thinking about what you used to be as a teacher and how much you... from placement, how much you've progressed in that way. Like what you were, or what you thought even before going into this, what you thought you wanted to be and now what I... how I know I want to teach and what teacher I want to be.

Several of the students were drawn to making connections between the activity of implicated reading and their own classroom practice. Student C, for example, offers the following insight:

I think the one for me was The Rainbow Fish, you know, looking at things from different points of view and how you can use text differently, you know when you pick something up you always think of the most obvious thing and I think sometimes that's why children get a bit bored in lessons because a lot of the time we do the thing that comes to us most naturally and we don't like to put ourselves in uncomfortable situations in case something goes wrong, whereas, when you're looking at it from different points of view it enables you to do that more. 
Commenting on the same text, Student E offers an explanation of an outcome that whilst focussed on classroom practice, was (to the author at least) unintended in terms of consequence.

The Rainbow Fish.... I'd never really thought about it in that way ... and if I go into school and read that book I'll always think you know, there's a different slant on this book and you know, I never would have thought that and even, I think, you know, I think that's one thing that I will take into school. I don't think I'll be able to read that book without thinking you know... I don't even think I'll read the book to be honest, so that definitely informed my practice.

\section{Discussion}

The responses above suggest two distinct but related possible outcomes for the students involved in the project. The first of these relates to the ways in which students articulate their understanding of text.

\section{Connectivity - texts as rhizomes}

As already established, texts are generally thought of as signifiers of meaning (Alvermann, 2000; Deleuze \& Guattari, 1987/2004; Pearce, 1997). Before the research project got underway, this way of understanding text was typically applied by the students as they made use of their written accounts. Journal writing, which described events in the classroom that students experienced, were taken as reflective starting points from where they would attempt to demonstrate development or growth in understanding in relation to particular aspects of their professional work. As such, the original text, in the form of a narrative of experience was relied upon to do the work of a signifier - to allow the student and their peers access to a given moment or moments in time from which they could work to improve upon for the future. This way of understanding and using text implies that in some way the text has successfully managed 'to capture the stuff that really counts - the meaning, the message, the ideas' (MacLure, 2003, p. 105). The resulting task for the reader here is a 
relatively straightforward one, in that as long as they can interpret the text 'correctly' they should be able to surmise its meaning without much difficulty. It is in the subsequent work that the demand lies, for once they have decided what the text means/its message, the students must begin to work on alternative actions that might have seen more satisfactory outcomes. However, there is a fly in the ointment here. A reminder of Brodkey's (1987) warning is useful at this juncture: a narrative of experience and experience itself are not one and the same.

Deleuze and Guattari's (1987/2004) view of text, a perspective which allows students to engage with and experience texts' connectivity, haunts the responses of Student A, B, C and D above. Student B, for example, articulates this in her dissatisfaction with 'surface' level work, which in her mind, leads to conclusions about who and what she is as a teacher ('well, I'm actually like this because of this... '). The implicated reading on the other hand, 'forces' her to reveal a 'subtext' - versions of herself and events that lie beyond the initial interpretations, meaning and message.

Student A's response ('That whole approach where you can use any source and you don't know where ideas are going to come from ... ') crystallises the rhizomatic effect. In the words of Deleuze and Guattari, the rhizome 'has neither beginning nor end, but always a middle from which it grows and overspills' (1987/2004, p. 23). Deleuze and Guattari ask us to consider the rhizome as a way of (un)ordering thought. It requires a move away from our habitual practice of thinking which has ensured that the world and our experiencing of 'reality' have been encountered, understood and written about as an ordered system or series of structured wholes from which taxonomies and typologies can be compiled (Colman, 2005). This recognition of the world has been pervasive. It has filtered the ways in which we have seen and experienced life. Our conception of reality is formed from, and is of, its making. Deleuze defines this as a world of representation or, more accurately, re-presentation 
- presenting the same world over and over again (Stagoll, 2005) because in stifling or limiting the nature of thought, the potential and possibility for something other to occur is similarly stifled and limited. In this world, variety and change are constrained to the extent that difference can only be experienced against the concept of sameness: 'difference-fromthe-same' (ibid.) which, not surprisingly, is not that different at all.

The rhizome offers an alternative conception as it has, in its makeup, the potential for presentation anew (rather than re-presentation). This is because, in its construction, it challenges habitual, structured and hierarchal thought. It exists in a state of perpetual creation. It constitutes an operation of things - movements, intensities and polymorphous formations (Colman, 2005). There is no structure or order to it but a series of complex, intertwined, overlapping and continually transforming 'random associations and connections...' and 'abstract relations between components' (Colman, 2005, p. 232). Student A's response suggests a state of thought that allows for this kind of 'perpetual creation' where 'ideas' come from anywhere at any time. Student A connects these to their personal life and writing. This seems to happen both consciously and subconsciously, as the student both intentionally attempts to 'make links' but also appears to experience what Masny (2013) refers to as a 'rhizomatic rupture' (as the student watches the American television serial, 'The Wire').

Student C and D also provide examples of 'random associations and connections' and 'abstract relations' between the various texts offered and their own experiences as documented in their journal writing. For Student C, identifying with the character of Amélie moves her to consider how facets of her nature impact on the ways she perceives events and actions. For Student D, the process results in a philosophical moment as she ponders the evolution of her teacher self. ('Like what you were, or what you thought even before going into this, what you thought you wanted to be and now what I... how I know I want to teach 
and what teacher I want to be.') In short, the students begin to experience a way of thinking, where ideas about who they are and how their teaching works occur between things and so are always emergent and always in a process of becoming; dependant on 'exteriority, motion, chance, and variation outside the contrived confines of a text'(St. Pierre, 1997, p. 409).

At this juncture, a key question one might ask is, in moving students away from a fixatedness on meaning and interpretation, what do we hope to achieve? In response to this concern, it is worth considering the postulations of Walter Benjamin (as cited in Britzman, 2003), who argues that there are two simultaneous dimensions to social life, the given and the possible and Britzman explains that, 'these dimensions become accessible to us when specific events, circumstances and dilemmas are viewed from a different perspective' (p. 222). Whilst working as a teacher educator, the author has observed students often search for 'the given' within their journal writing, the presence of 'the possible' at best seeming analogous to background noise; present, but turned down or tuned out (rather than consciously accessed) for worry it might confuse or detract from 'the given'. Roy (2003), as part of his research which applies Deleuzian praxis to the reinvention of school curricula, alerts us to several good reasons as to why this process of 'tuning out' needs to be confronted. Drawing on Deleuze (1968/2004), he also notes the over-reliance on a model of thought embedded within and derived from the traditions of western philosophy; those of representationalism where thought is a faithful interior representation of the outside world and, consequently, recognition becomes its chief tool of execution. This process of recognition (in education at least) is governed by 'several regimes of signifiers [for example:] objective assessment, competence, risk, standardisation...' (Roy, 2003, p. 11), all of which find legitimation in their own self-images. The result, for the student teacher, is the loss of other ways of looking, feeling, thinking and doing - triumphs for the circular, self-referential repetition. This process could often be observed in the students' critical reflections upon their journal writing as a 
chain of thinking depicted (rather crudely) as follows: 'What is going on here?' (= Interpretation). 'What categories do I have to recognise these actions in the outside world of teaching e.g. personalisation, assessment, effective parent/teacher relations etc.?' (= Recognition). 'How do those categories help me understand what happened and/or what should have/might have happened? (= Repetition). The limitations of these familiar cognitive associations are explained by Deleuze (1968/2004):

'....representation fails to capture the affirmed world of difference. Representation only has a single centre, a unique and receding perspective and in consequence a false depth. It mediates everything but mobilizes and moves nothing.' (p. 55-56)

According to Deleuze (1968/2004) then, what is restricted in this model is movement itself. This is because the recognition involves the evocation of pre-existing categories and boundaries that define what school life, teaching, learning, etc. can and should look like. Any 'movement' is therefore confined to a pre-ordered system of signification. Moving beyond these 'confining spaces' (Roy, 2003) demands a different mode of perception. It requires a manner of looking that cannot be derived from the old system of thought as representation. Roy (2003) is clear; as educators it is an ethical necessity that we free ourselves from these totalising and self-perpetuating signifiers and categories that code and confine thought and action. This argument can be extended. Do teacher educators not have a duty of care towards their students to foster the same? To provide/suggest/exemplify the means by which we might perceive educational contexts in ways that allow at least glimpses of Walter Benjamin's 'world of possibilities' (as cited in Britzman, 2003) that exists outside of a sign regime that controls and limits? It might be argued that this is not only desirable for teacher educators, but a moral imperative. Whilst it is impossible to measure the extent to which implicated reading allowed students to think in ways less prone to the wiles of representationalism, it certainly offered them the opportunity to draw upon a range of 
categories of recognition in addition to those usually associated with the teaching and learning encounter. For some students this resulted in a reconsideration of their teacher self as presented in their journal writing which suggested engagement with a hinterland beyond the confining spaces of recognition. For example, Student C, who ponders her need for reassurance and her propensity for worry and dramatization ('I kind of dramatise things in my head and I worry about that the smallest things... ').

It would be foolish however to assume that experiencing these texts and thus reflection as rhizomorphous is necessarily a positive experience, as we see in the response of Student E, for whom The Rainbow Fish has caused consternation. As a result of the implicated reading activities, Student E considers the text of The Rainbow Fish in new, possibly less settled ways ('I'd never really thought about it that way before'). Perhaps not wanting to confuse her would-be future pupils with a text whose meaning now seems less important or stable, she decides that reading this, now highly suspect text, is best to be avoided.

\section{Rethinking pedagogy}

Student E's suspicion towards the classic children's text leads us to consider the second possible outcome for the students involved in the project; the ways in which implicated reading encourages students to rethink classroom practice.

When teaching is defined by and reduced to lists of competencies and skills to be acquired in order to be effective we find that, without check, a standardised and reductionist story of teaching begins to infect our understanding of what learning to be a teacher is about (O’Conner, 2008). This process constructs a powerful 'right/wrong' binary, one which creates fear and anxiety amongst students, especially during teaching practice, as they try to reproduce the 'right' kind of teaching for those that observe and judge them. Within such a 
constrained conception of practice there is limited tolerance of mistakes and so the work of the student teacher becomes that of minimising the potential for things to go wrong. Of course, the binary is false. There is no right and wrong way to teach; too many variables are at play for this to be possible. Some techniques will work better than others; some will prove effective one week and then seem ineffectual the next; some will appear as acts of sheer brilliance when performed by one teacher, only to seem awkward and staged when taken up by another - this is why learning to teach, or teacher 'becoming' is a heterogeneous process and one that should necessarily involve trial and error. However, the right/wrong myth lives on. In the response of Student $\mathrm{C}$ above, we can see her ponder this false binary and its effects as she describes the decisions she makes regarding classroom activity as being constrained by her concern to avoid the potential for things to go wrong ('...we don't like to put ourselves in uncomfortable situations in case something goes wrong').

What is particularly interesting in Student C's comments is her reference to teaching methods that come 'naturally'.

...you know when you pick something up you always think of the most obvious thing and I think sometimes that's why children get a bit bored in lessons because a lot of the time we do the thing that comes to us most naturally...

The use of the adverb 'naturally' suggests a recourse to an innate and inherent practice that student teachers (in the plural, signified by Student C's use of the pronoun 'us') tend to fall back or rely upon in their everyday teaching activities; as if a particular framework for 'being a teacher' is coded into their DNA. This 'naturalistic' form of teaching is a perfect delusion. Whilst neither belonging to us, nor created by us, we feel certain notions of, or practices for, teaching behaviour are bound into our very fabric as teachers. 'Natural teaching' is seductive, its presence providing a 'semblance of order, control and certainty in the face of the uncertainty and vulnerability of the teachers' world' (Britzman, 2003, p. 222). 
There is something quite understandably comforting about such a proposition. Being and doing what a teacher should be, or do, is a reward and safe space in and of itself and all at once. However, what feels 'natural' is actually method: ways of delivering learning that are preformed and structured means to specified ends. The repetitive nature of such pedagogies, acquired via a process Britzman describes as 'imitation, recitation and assimilation' (2003, p. 46) may well be comforting, but it is also limiting, not only for the student teacher, but as noted by Student $\mathrm{C}$, to the children they teach. What appears to be 'right', 'natural' and comfortable can also be 'boring'. The abundance of formulas for 'success' provided for teachers ultimately increase the potential for 'success' to become formulaic. This formula, whilst providing structure and safety for the class teacher (and the children) works to minimise the potential for difference and in doing so teaching and learning activities stagnate or become 'boring'.

Student C's recollection of her implicated readings and the realisation that a text can be viewed from a perspective of difference, rather than repetition ('the most obvious thing') as Masny (2013) explains, can be a liberating process; 'Reading [rhizomatically and in the Deleuzian sense], that is, plugging in, takes away the anxiety about getting it (meaning, interpretation) right' (p. 340). This sense of liberation allows Student C to begin to wonder whether putting herself in an uncomfortable situation, or in other words, deviating from that which comes 'naturally', might be a strategy which also provides positive outcomes for the children she teaches. This is a view of learning and, indeed, learning to teach, which draws less on the accepted orthodoxy of interpretation, recognition and repetition, and more on a view of learning as unpredictable and uncertain (and therefore probably uncomfortable). For Student $\mathrm{C}$ at least, the implicated read as a method appears to allow an insight into what might be possible when we look beyond the obvious and see that learning to teach and learning to learn, involves taking risks and venturing away from what seems instinctive. 


\section{Concluding thoughts}

It is difficult to generalise about the success (or otherwise) of a project that involves reflection, not least because, as Korthagen notes (2001, as cited in Collin, Karsenti, \& Komis, 2013), reflection tends to happen inside one's own head. In part, the project sought to address this problematic, encouraging the student teachers to articulate the reflective process (both as part of the implicated reading activities as well as in subsequent interviews), and on this basis perhaps some tentative conclusions about the implicated reading project can be drawn.

However, as several of the participants explained or suggested, reflection was not confined to the implicated reading activities, nor, indeed to the physicality of the university environment. This was described in the analysis above as the rhizomatic effect, where reflective thought is triggered through a process of connectivity, reaching beyond the confines of text, the lived experience and the common signifiers of a given professional context. In summary, it might well be argued that the reflective activities designed as part of the project were intended and in some cases succeeded in transforming reflective thought. This seems potentially significant. Deleuze and Guattari (1987/2004) are clear in their foregrounding of thought as a contested space, one where the threat of colonisation by the state ${ }^{2}$ looms large. They write:

\footnotetext{
'In a sense, it could be said that all this has no importance, that thought has never had anything but laughable gravity. But that is all it requires: for us not to take it seriously. Because that makes it all the easier for it to think for us, and to be forever engendering new functionaries. Because the less people take thought seriously, the more they think in conformity with what the state wants.' (p. 415)
}

\footnotetext{
${ }^{2}$ In Deleuzo-Guattarian (1987/2004) terms, the state is sovereignty. It reigns over what it is capable of internalising. Its goal is to reproduce itself.
} 
It seems that one thing that might be said about the project is that it allowed the students to take reflective thought seriously. To consider how it might be done differently, for what purpose and to what end. Creating the conditions which allow for students to question the way they think/reflect, provides the "weapons ${ }^{3}$ necessary in the construction of an alternative mind-set; loosening the grip of conformity and opening up the students' thought patterns to difference. It seems in the process of rethinking reflection and consequently their practice and teacher selves these effects, are, for the student teacher, worthy of pursuit.

\section{References}

Alvermann, D. A. (2000). Researching Libraries, Literacies, and Lives: A Rhizoanalysis. In E. A. St. Pierre \& W. S. Pillow (Eds.), Working the Ruins: feminist poststructural theory and methods (pp. 258-283). New York, NY: Routledge.

Beauchamp, C. \& Thomas, L. (2010). Reflecting on an ideal: student teachers envision a future identity. Reflective Practice. 11, 631-643.

Britzman, D. P. (2003). Practice Makes Practice: A critical study of learning to teach. Revised edition. Albany, NY: University of New York Press.

Brodkey, L. (1987). Academic Writing as a Social Practice. Philadelphia, PA: Temple University Press.

Clandinin, D. J., \& Connelly, F. M. (2000). Narrative Inquiry: Experience and story in qualitative research. San Francisco, CA: Jossey-Bass.

Collin, S., Karsenti, T., \& Komis, V. (2013). Reflective practice in initial teacher training: critiques and perspectives. Reflective Practice, 104-117.

Colman, F. J. (2005). Rhizome. In A. Parr (Ed.), The Deleuze Dictionary (pp. 231-233). Edinburgh: Edinburgh University Press.

\footnotetext{
${ }^{3}$ The use of the noun 'weapon' is purposeful. In 'A Thousand Plateaus', Deleuze and Guattari (1987/2004) distinguish tools from weapons. Tools belong to the state apparatus, whereas weapons are of the nomad. Weapons are likened to jewellery. They share an essential relation small moveable objects, easily transported and pertaining to the object only as an object in motion. They also lend colour, 'turning gold to red and silver to white light' (p. 443).
} 
Cowan, J. (2014). Noteworthy matters for attention in reflective journal writing. Active Learning in Higher Education. 15, pp. 53-64.

Deleuze, G. (1968/2004). Difference and Repetition. London: Continuum International.

Deleuze, G., \& Guattari, F. (1987/2004). A Thousand Plateaus: Capitalism and schizophrenia. London: Continuum International.

Farrell, T. S. C. (2013). Teacher self-awareness through journal writing. Reflective Practice, $14,465-471$.

Gale, K. (2007). Teacher education in the university: working with policy and practice and Deleuze. Teaching in Higher Education. 12, pp. 471 - 483.

Gale, K. (2010, July). Putting Deleuze to Work. Paper presented at the meeting of the Education and Social Research Institute, Summer Institute in Qualitative Research, Manchester Metropolitan University, The Business School, Manchester.

Gilbert, P. (1989). Writing, schooling, and deconstruction. London: Routledge.

Holly, M. L. (1989). Writing to Grow: Keeping a personal-professional journal. Portsmouth: Heinemann Educational Books.

Kemmis, S., \& McTaggart, R. (2000). Participatory Action Research. In N. K. Denzin \& Y. S. Lincoln (Eds.), Handbook of Qualitative Research. 2nd edition (pp. 567-605). London: Sage Publications.

MacLure, M. (2003). Discourse in Educational and Social Research. Buckingham: Open University Press.

Magnusson, E., \& Marecek, J. (2015). Doing Interview-based Qualitative Research: A Learner's Guide. Cambridge: Cambridge University Press.

Masny, D. (2013). Rhizoanalytic Pathways in Qualitative Research. Qualitative Inquiry, 19, $339-348$.

Mazzei, L.A., \& McCoy, K. (2010). Introduction: Thinking with Deleuze in qualitative research. International Journal of Qualitative Studies in Education, 23, 503-509.

McGarr, O., \& Moody, J. (2010). Scaffolding or stifling? The influence of journal requirements on students' engagement in reflective practice. Reflective Practice,11, $579-591$.

Mitchell, E. (2001, November 2). Amelie (2001) Film Review; Little Miss Sunshine as Urban Sprite. The New York Times. Retrieved from http://www.nytimes.com/movie/review?res=9B03EEDD1130F931A35752C1A9679C $\underline{8 \mathrm{~B} 63}$ 
Nelson, F. L., \& Sadler, T. (2013). A third space for reflection by teacher educators: A heuristic for understanding orientations to and components of reflection. Reflective Practice, 14, 43-57.

Noffke, S., \& Somekh, B. (2005). Action Research. In B. Somekh \& C. Lewin (Eds.) Research Methods in the Social Sciences. (pp. 89-96). London: Sage Publications.

O'Connell, T.S., \& Dyment, J.E. (2011). The case of reflective journals: is the jury still out? Reflective Practice, 12, 47-59.

O'Conner, K. E. (2006). "You choose to care": Teachers, emotions and professional identity. Teaching and Teacher Education, 24, 117-126.

Ossard, C. (Producer), \& Jeunet, J.-P. (Director). (2001). Amélie [Motion picture]. France: $20^{\text {th }}$ Century Fox.

Pearce, L. (1997). Feminism and the Politics of Reading. London: Arnold.

Pfister, M. (1996). The Rainbow Fish. New York, NY: North-South Books.

Rowling, J. K. (1997). Harry Potter and the Philosopher's Stone._Bloomsbury: London.

Roy, K. (2003). Teachers in Nomadic Spaces: Deleuze and Curriculum. New York, NY: Peter Lang.

Saldaňa, J. (2014) Coding and Analysis Strategies. In P. Leavy (Ed.) The Oxford Handbook of Qualitative Research. (pp. 581-605). New York, NY: Oxford University Press.

St. Pierre, E. A. (1997). Circling the text: nomadic writing practices. Qualitative Inquiry, 3, 403-417.

Somekh, B. (2006). Action Research: A Methodology for Change and Development. Berkshire: Open University Press.

Somekh, B., Burman, E., Delmont, S., Meyer, J., Payne, M., \& Thorpe, R. (2005). Research Communities in the Social Sciences. In B. Somekh \& C. Lewin (Eds.) Research Methods in the Social Sciences. (pp. 1-13). London: Sage Publications.

Stagoll, C. (2005). Becoming. In A. Parr, A. (Ed.), The Deleuze Dictionary (pp. 21-23). Edinburgh: Edinburgh University Press. 